\title{
Stage IV Vulvar Cancer AJCC v8
}

National Cancer Institute

\section{Source}

National Cancer Institute. Stage IV Vulvar Cancer A/CC v8. NCI Thesaurus. Code C139627.

Stage IV includes: T1-T3, N3, M0-M1. T1: T umor confined to the vulva and/or perineum. Multifocal lesions should be designated as such. The largest lesion or the lesion with the greatest depth of invasion will be the target lesion identified to address the highest pT stage. Depth of invasion is defined as the measurement of the tumor from the epithelialstromal junction of the adjacent most superficial dermal papilla to the deepest point of invasion. T2: T umor of any size with extension to adjacent perineal structures (lower/distal third of the urethra, lower/distal third of the vagina, anal involvement). T3: Tumor of any size with extension to any of the following: upper/proximal two-thirds of the urethra, upper/proximal two-thirds of the vagina, bladder mucosa, or rectal mucosa; or fixed to pelvic bone. N3: Fixed or ulcerated regional lymph node metastasis. M0: No distant metastasis. M1: Distant metastasis (including pelvic lymph node metastasis). (from AJCC 8th Ed.) 